\title{
ANATOMY AND IMAGING APPEARANCES OF COMMON PATHOLOGIES OF THE PITUITARY REGION: A PICTORIAL REVIEW
}

Sitheeque $\mathrm{F}^{1}$, Udupihille $\mathrm{JJKH}^{2}$, Amarasinghe VGPS ${ }^{1}$

${ }^{1}$ Department of Radiology and Medical Imaging, Teaching Hospital, Kandy, Sri Lanka

${ }^{2}$ Department of Radiology, Faculty of Medicine,University of Peradeniya, Sri Lanka

DOI: http://doi.org/10.4038/sljr.v2i2.49

Key words:Pituitary gland, Pituitary diseases, sellar and suprasellartumours, MRI of pituitary

\section{INTRODUCTION}

The sellar region is an anatomically complex area where a variety of neoplastic, developmental, inflammatory and vascular pathologies occur. Even small lesions in this region can lead to significant clinical consequences including hormonal imbalances, visual defects and obstructive hydrocephalus due to mass effect on adjacent important structures.

Plain skull radiographs are insensitive and are infrequently used for diagnosing pituitary region pathology. CT and MRI are the mainstay in diagnosis of pathology in this region. Currently, MRI is the imaging modality of choice due to its superior soft tissue delineation and pathological characterization ${ }^{1}$.

\section{RADIOLOGICAL ANATOMY}

The pituitary gland and the inferior part of the stalk lie within the sellaturcica, a bony fossa in the basisphenoid bone. Inferior to the sellaturcica is the sphenoid sinus(Figure1). The suprasellar cistern has the circle of Willis, optic chiasma and the upper part of the pituitary stalk. The hypothalamus and infundibular recess of third ventricle are seen above this.

The cavernous sinuses lie on either side of the sella turcica. The internal carotid artery and abducent nerve lie within the cavernous sinus. The oculomotorand trochlearnerves, ophthalmic as well asmaxillary divisions of trigeminal nerve lie within the lateral wall.

Corresponding Author: Sitheeque F, <farihasitheeque@gmail.com>

(iD) http://orcid.org/0000-0002-3813-2346

(1) This is an open-access article distributed under the terms of the Creative Commons Attribution License, which permits unrestricted use, distribution, and reproduction in any medium, provided the original author and source are credited. 
The pituitary gland has a larger anterior lobe and a smaller posterior lobe. The anterior lobe appears isointense to grey matter on both T1W, T2W images $^{2}$. The posterior pituitary has intrinsic high T1 signal in $90 \%$ (pituitary 'bright spot') and is usually hypointense on T2W images(Figure $2)^{3,4}$.The normal gland and stalk show homogenous contrast enhancement. ${ }^{4}$

The size of the pituitary gland varies with gender, age and physiological status. 'Elster's rule' of $6,8,10,12$ is a useful guide to normal gland height: $6 \mathrm{~mm}$ for infants and children, $8 \mathrm{~mm}$ in men and postmenopausal women, $10 \mathrm{~mm}$ in women of reproductive age and $12 \mathrm{~mm}$ for women in late pregnancy or postpartum ${ }^{3}$.The normal pituitary stalk has a thickness of 2 to $4 \mathrm{~mm}$ or equal to or less than the diameterof the Basilar artery ${ }^{1}$.

\section{IMAGING MODALITIES}

The radiographic size of the sella on plain $\mathrm{X}$-rays is not an accurate indicator of pituitary gland abnormality ${ }^{1}$.Cross-sectional imaging demonstrates anatomy and pathology of this region well. CT imaging of the pituitary region is performed with noncontrast followed by contrast-enhanced CT and multiplanar reconstruction of images. CT demonstrates calcifications and bony details better than MRI and plays a major role in patients who are contraindicated for MRI.

3T MRI is superior to $1.5 \mathrm{~T}$ MRI for imaging of the pituitary region ${ }^{5}$. MR images are acquired as thin sections of $3 \mathrm{~mm}$ in sagittal and coronal planes on $\mathrm{T} 1 \mathrm{~W}, \mathrm{~T} 2 \mathrm{~W}$ spin-echo sequences using a small FOV and high resolution matrix ${ }^{1}$. Small lesions may only be seen followingiv Gadolinium-DTPA enhancement.Dynamic MRI is the technique of choice for diagnosing microadenomas.In dynamic imaging thin sections of $2.5 \mathrm{~mm}$ are acquired in coronal plane after a bolus of $0.05 \mathrm{ml} / \mathrm{kg}$ intravenous Gadolinium ${ }^{1}$.

\section{PATHOLOGY}

\section{Pituitary Macroadenoma}

Pituitary macroadenomas are tumours measuring more than $10 \mathrm{~mm}$ in size $\mathrm{e}^{4}$ They are the most commonly diagnosed tumour of this region in adults. ${ }^{6}$ As they grow, they first expand the sellaturcica(94-100\%) ${ }^{6}$ and then grow upwards, characteristically giving rise to a 'snowman' or 'figure of 8' appearance due to indentation by the diaphragmasella(Figure 3$)^{4}$.

Macroadenomas are typically isointense to grey matteron both $\mathrm{T} 1 \mathrm{~W}$ and $\mathrm{T} 2 \mathrm{~W}$ images ${ }^{2}$.They demonstrate inhomogenous moderate to bright enhancement with IV contrast(Figure 4$)^{4}$. Signal characteristics vary depending on the presence of haemorrhage, cystic change or necrosis. (Figure5).Areas of necrosis, cystic change or hemorrhage are often seen in larger adenomas $^{2,4}$.Intra-tumouralhaemorrhage is more frequent in macroadenomas than in other tumours of this region ${ }^{7}$.T2* gradient echo is sensitive for detecting haemorrhage.Calcification is rare ${ }^{7}$.

Cavernous sinus invasion can occur and is assessed based on degree of encasement of the internal carotid artery. Encasement of less than 90 degrees makes invasion very unlikely, whereas more than 270 degrees indicates invasion with high certainty(Figure $6)^{4}$.

\section{Pituitary Microadenoma}

Pituitary adenomas less than $10 \mathrm{~mm}$ in size are considered as microadenomas. A microadenoma is seen only in $70 \%$ of scans without IV contrastmedium and may appear as a bulge in the outline of the gland ${ }^{4}$. Dynamic MR imaging can reduce the falsenegative rate and facilitate diagnosis ${ }^{8}$.The typical enhancement pattern is centrifugal, first in the stalk and gradually the entire 
anterior lobe ${ }^{1}$.Homogenous enhancement and maximum image contrast between normal pituitary and microadenoma occurs between 30-60 s(Figure7) ${ }^{8}$.Microadenomas are relatively nonenhancing at this stage and appear hypointense within an enhancing pituitary gland(Figure 8$)^{1,8}$. They show delayed enhancement and the peak enhancementoccurs between 60-200s ${ }^{8}$.A further delayed image may demonstrate microadenoma as a hyperintense lesion ${ }^{1}$.

\section{Craniopharyngioma}

This tumour arises from embryonic remnants of Rathke pouch and most frequently occurs in childhood with a further peak in the $6^{\text {th }}$ decade ${ }^{6}$.

There are two histological types with different imaging appearances. The adamantinomatous type $(90 \%)$ occurs in any age group but most often in children. It has cystic components and calcifications in majority $(90 \%)$ (Figure 9). The papillary type(10\%) which occurs in adults has cysts or calcifications less commonly ${ }^{6,9}$.

The epicenter of craniopharyngiomas is usually suprasellar. Extension into the sella is common but it expands the fossa only when it is very large. A purely intrasellar lesion is rare ${ }^{9}$ The tumour frequently compresses the thirdventricle resulting in obstructive hydrocephalus.MRI appearance is usually pathognomonic in children due to heterogenous signal characteristics (Figure10).

On T1W images cysts in adamantinomatous type are iso- to hyperintense to brain due to high protein content(Figure11). T2W signal intensity is variable but about $80 \%$ are hyperintense. Solid components show vivid enhancement. Cysts when present in the papillary type show low T1 signal intensity similar to $\mathrm{CSF}^{9}$.

\section{Rathkecleft cyst}

Occasionally a remnant of Rathke pouch could persist after post-natal period and later in life may give rise to a Rathke cleft cyst. It is usually an incidental finding and becomes symptomatic only if large. There is a female preponderance and it is rarely seen in children ${ }^{10}$.It is most commonly located within the anterior lobe of the pituitary but may frequently occur in suprasellar location too ${ }^{10}$.

CT appearance is of a homogenous low attenuation lesion(Figure12). Calcification of the cyst wall occurs rarely ${ }^{11}$. On MRI, T1W signal characteristics vary with cyst content. It may be of high intrinsic signal intensity due to proteinaceous material or appear similar to CSF. T2W signal intensity is $\operatorname{variable}^{2}$ (Figure 13) $^{11,1}$. The cyst itself does not enhance but the cyst wall may do so(Figure; 14) ${ }^{12}$.An intra-cystic nodule is characteristic, occurring in about $75 \%$ of cases aiding to differentiate this from a cystic macroadenoma ${ }^{12}$.

\section{Meningioma}

This is the secondmost common tumor in the pituitary region. It most often occurs in middle-aged women ${ }^{2}$.Meningiomas of this region usually occur in suprasellar location ${ }^{2}$.

On CT, meningiomas appear iso- to hyperdense with avid, homogenous contrast enhancement ${ }^{6}$ (Figure 15). In contrast to macroadenomas ballooning of the sella is less common with meningiomas(Figure 16) ${ }^{6}$.Hyperostosis of adjacent bone is highly specific for meningiomas, but is seen only in $34 \%^{2,6}$.A CSF cleft between tumor and pituitary gland is specific for asellar meningioma and virtually excludes macroadenoma ${ }^{6}$. Calcifications, cysts and hemorrhage are atypical features ${ }^{2}$.Cavernous sinus invasion occurs in about $18 \%^{2,6}$. 
Meningiomas are usually isointense to gray matter on both T1W,T2W images.Marked homogenous enhancement is characteristic of meningiomas ${ }^{2}$.They commonly have obtuse dural margins and linear enhancement of adjacent dura ("dural tail sign") in about $68 \%$, which are known to be typical of meningiomas(Figure 17) $)^{2,6}$. Flow voids and peritumoraloedema are also common in them ${ }^{2}$.

\section{Empty Sella}

This may be an incidental finding on MRI or the patient may have symptoms similar to the presence of a mass in this region.

CSF is found filling the sella and may mimic a cystic macroadenoma ${ }^{13}$. Thesella is usually enlarged and thinned out without destruction. The infundibulum traverses the CSF-filled sella without displacement "the infundibulum sign"(Figure 18) . "Total" empty sella is when more than $50 \%$ of sella is filled with CSF and the gland is compressed to less than $2 \mathrm{~mm}^{14}$.It is 'partial' when less than $50 \%$ of the sella is filled with CSF. Pituitary gland height ranges from 3$7 \mathrm{~mm}^{14}$.

Primary empty sella occurs in combination of increased CSF pressure and a defect/incomplete diaphragmasella (normal variant) and is found in pregnancy, obesity and idiopathic intracranial hypertension ${ }^{14}$.

Secondary empty sellaisdue to regression of the pituitary gland after surgery or radiotherapy or in apoplexy ${ }^{14}$.

\section{Supra and parasellar aneurysms}

The parasellar region is the most common location for giant intracranial aneurysms measuring more than $2.5 \mathrm{~cm}^{2}$.Aneurysms of cavernous, supraclinoidinternal carotid artery may present as visual field defects.
CT usually shows dense homogenous enhancement of the aneurysm, but it is heterogenous when partially thrombosed. (Figure19)Sellar erosion can occur and rarely it mayextend into the sella, enlarging it $^{2,6}$.

MRI has superseded CT cerebral angiography due its sensitivity to changes in flow and hemoglobin degradation products $^{2}$.Involvement of vessels and MRI appearances are usually characteristic enough to waive off the need for MR angiography for diagnosis ${ }^{2,6}$.

T1 hyperintensity is caused by subacute thrombus or flow related enhancement. T2 hypointense areas are caused by intracellular deoxy- or methhemoglobin,calcifications or flow voids in a patent lumen. Peripheral crescentic lamellae may be seen due to Haemoglobindegradation products in the thrombus (Figure 20) 2,6 .

\section{Conclusion}

Lesions in the pituitary region can have overlapping imaging features. This may lead to difficulties in differentiation between them. However, the knowledge of certain imaging findings specific to a particular pathology can lead to a more accurate diagnosis.Thus a good knowledge in anatomy and imaging appearances of the common pathologic lesions in this region is vital.

\section{Acknowledgments}

Our special thanks go to Dr.U.G.Rodrigo (MD), Consultant Radiologist and Head, Department of Radiology and Medical imaging, Teaching Hospital, Kandy for granting permission to obtain images used in this article and to Dr.B.A.D.Jayanthan for technical support. 


\section{References}

1. Chaudhary V,Bano S. Imaging of the pituitary: Recent advances. Indian Journal of Endocrinology and Metabolism. 2011; 15(Suppl3): S216-S223.

2. Johnsen DE, Woodruff WW, Allen IS, Cera PJ, Funkhouser GR, Coleman LL. MR imaging of the sellar and juxtasellar regions. Radiographics. 1991;11:727-58

3. Elster AD. Imaging of the sella: Anatomy and pathology. Seminars in Ultrasound CT and MRI. 1993;14:182-94.

4. Pisaneschi M, Kapoor G. Imaging the sella and parasellar region. Neuroimaging Clinics of North America. 2005;15 (1): 203-19.

5. Louis JK, Gregory PL, William LW, John K. Preliminary experience with 3-Tesla MRI and cushing's disease. Skull Base. 2007; 17:273-7.

6. Donovan JL and Nesbit GM. Distinction of masses involving the sella and suprasellar space: specificity of imaging features. American Journal of Roentgenology. 1996;167:597-603.

7. Tosaka M et al. Assessment of Hemorrhage in Pituitary Macroadenoma by $\mathrm{T} 2 *_{-}$ Weighted Gradient-Echo MR Imaging. American Journal of Neuroradiology. 2007;28(10):2023-2029.

8. Sakamoto $\mathrm{Y}$, Takahashi M, Korogi $\mathrm{Y}$, Bussakhi H, Ushio Y. Normal and abnormal pituitary glands: Gadopentatedimeglumine enhanced MRimaging. Radiology. 1997;178:441-5.
9. Sartoretti-Schefer S, Wichmann W, Aguzzi A et-al. MR differentiation of adamantinous and squamouspapillarcraniopharyngiomas. American Journal of Neuroradiology. 1997;18 (1):77-87.

10. Crenshaw WB, Chew FS. Rathke's cleft cyst. American Journal of Roentgenology. 1993;158:1312.

11. Kucharczyk W, Peck WW, Kelly WM et-al. Rathke cleft cysts: CT, MR imaging, and pathologic features. Radiology. 1987;165 (2): 491-5.

12. Byun WM, Kim OL, Kim D. MR imaging findings of Rathke's cleft cysts: significance of intracystic nodules. American Journal of Neuroradiology. 2000;21(3): 485-8.

13. Haughton VM, Rosenbaum AE, Williams AL et-al. Recognizing the empty sella by CT: the infundibulum sign. American Journal ofRoentgenology. 1981;136 (2): 293.

14. Aruna P, SowjanyaB, Amaresh Reddy P, Krishnamma $M$, and Naidu JN. Partial Empty Sella Syndrome: A Case Report and Review. Indian Journal of Clinical Biochemistry. 2014 Apr; 29(2):253-256. 

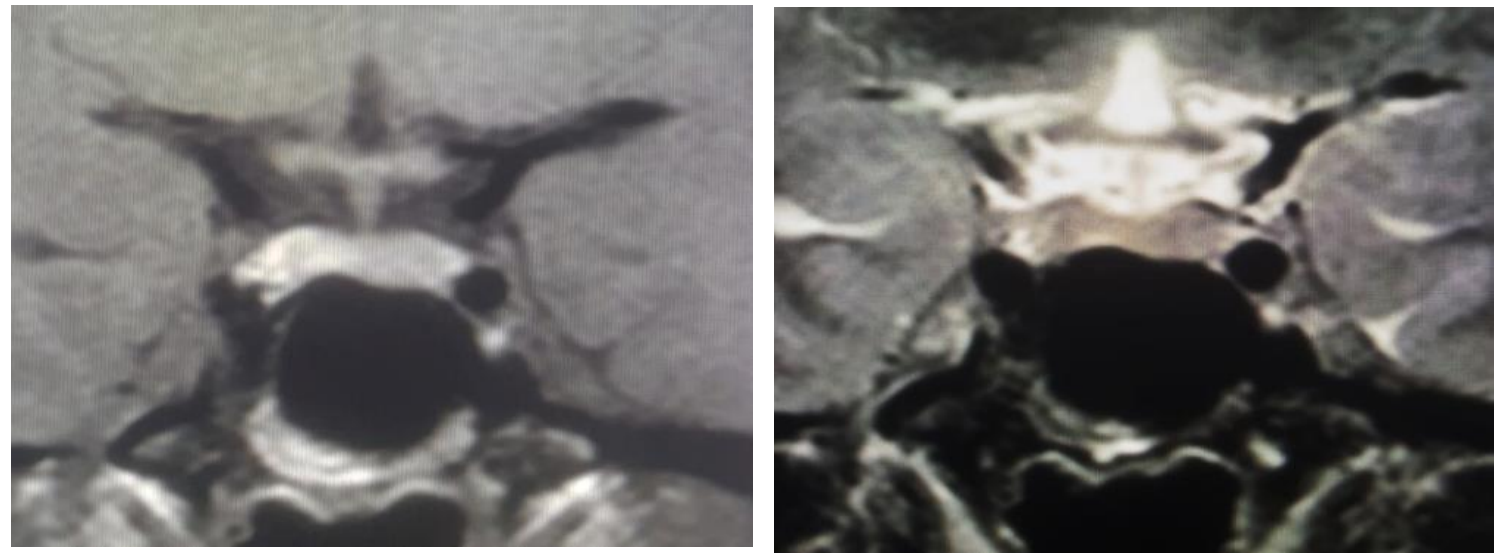

Figure 1:T1W, T2W MRI showing normal anatomy of sellar region
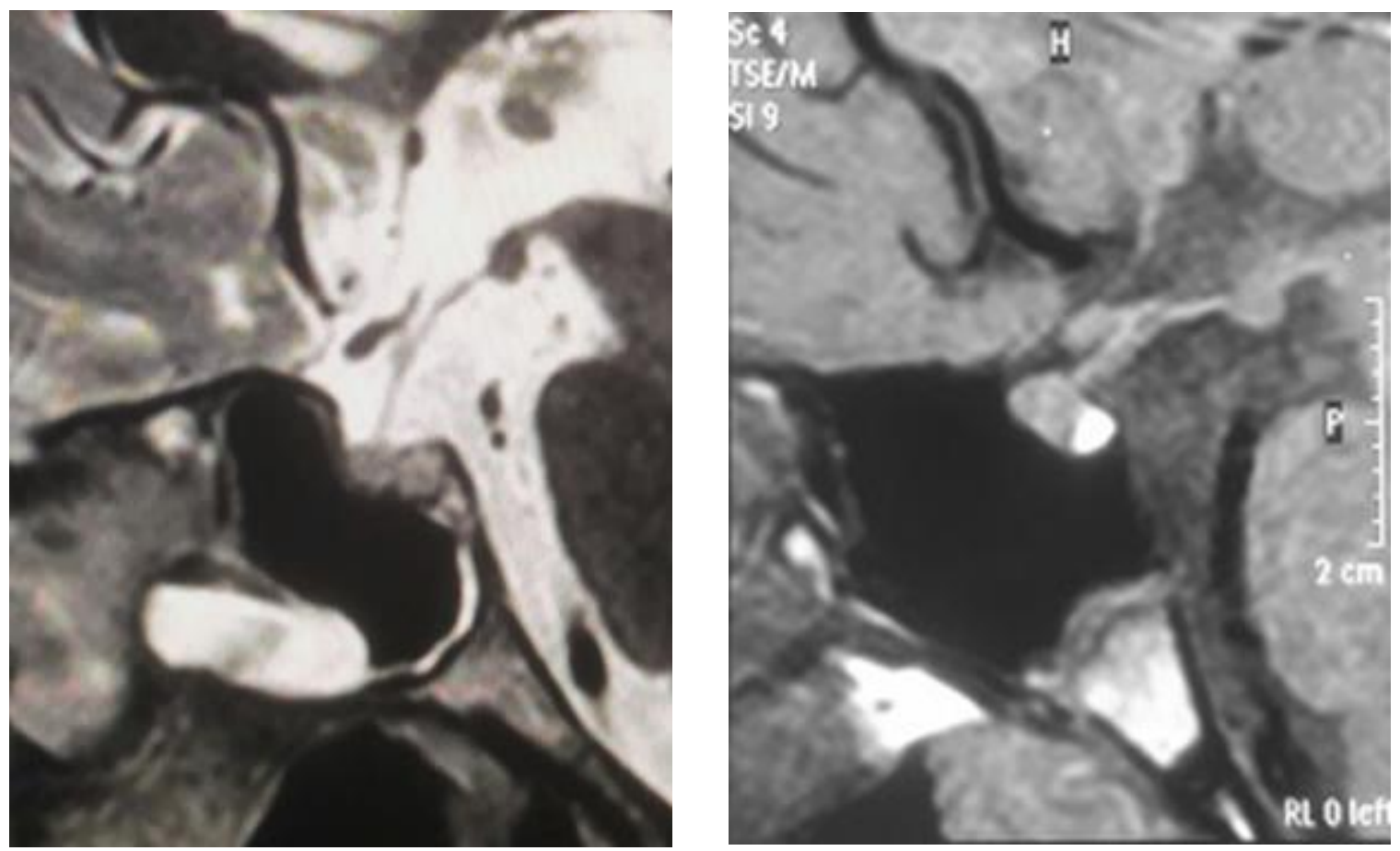

Figure2:T2W,T1W images: pituitary gland, stalk and infundibular recess of $3^{\text {rd }}$ ventricle. Note the 'bright spot' of posterior pituitary on T1W image 

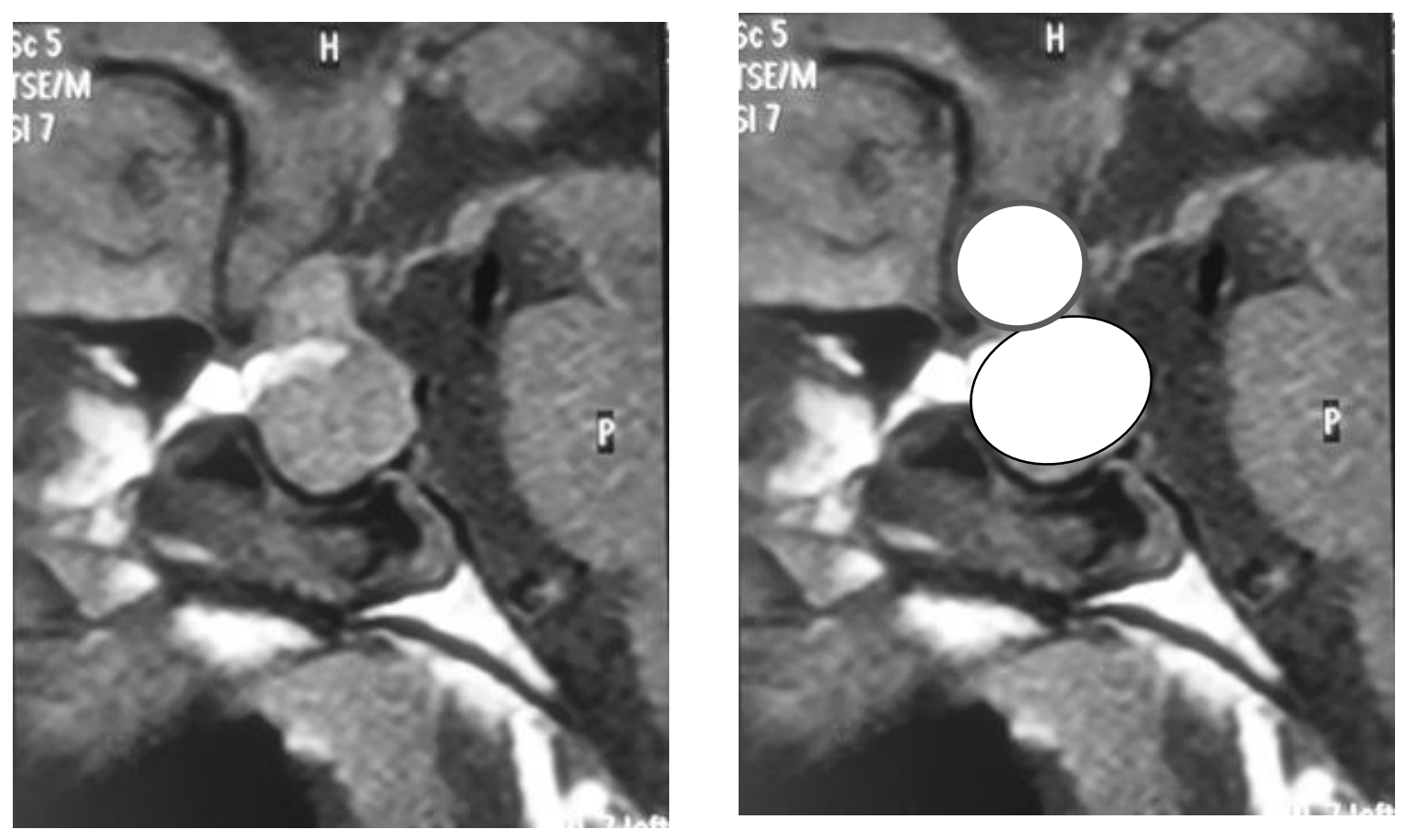

Figure 3: Typical "Snow man" appearance of macroadenoma

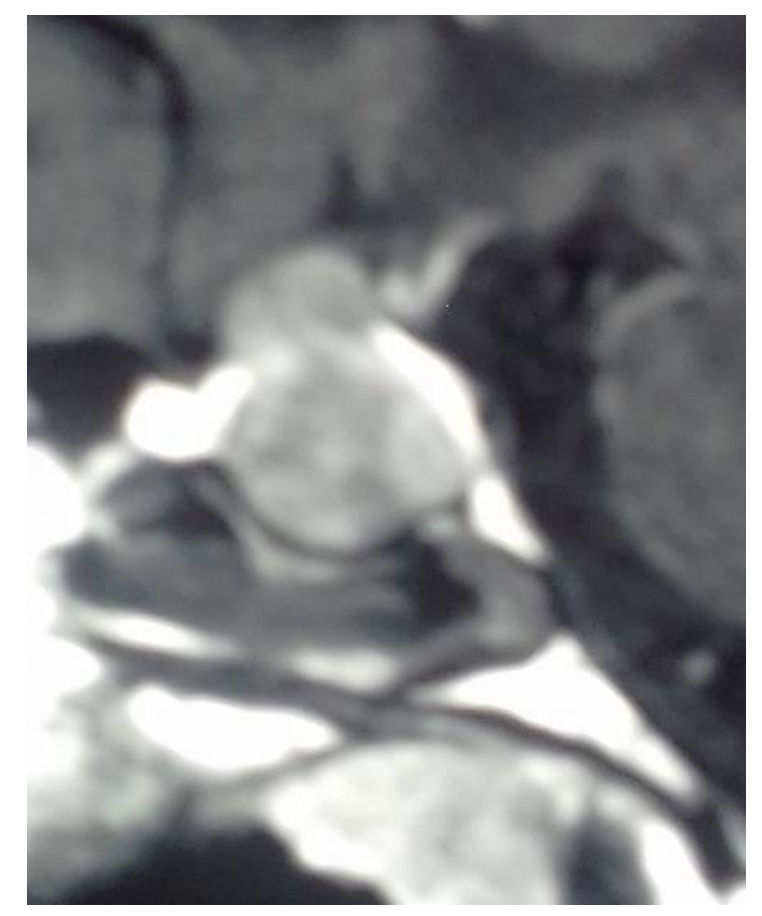

Figure 4: Moderate enhancement of a macroadenoma 

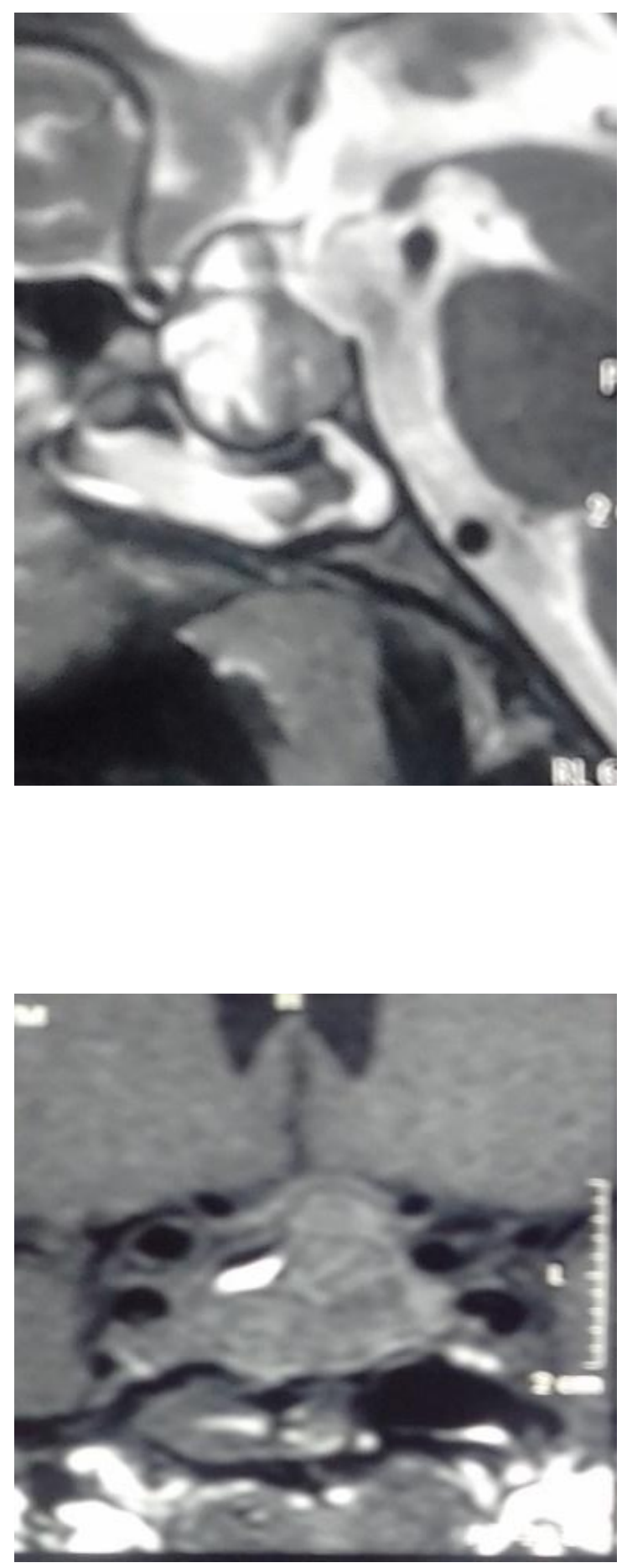

Figure 5: Cystic change and a fluid-fluid level indicating haemorrhage

Figure 6: Expansion of sella and $R /$ cavernous sinus invasion 


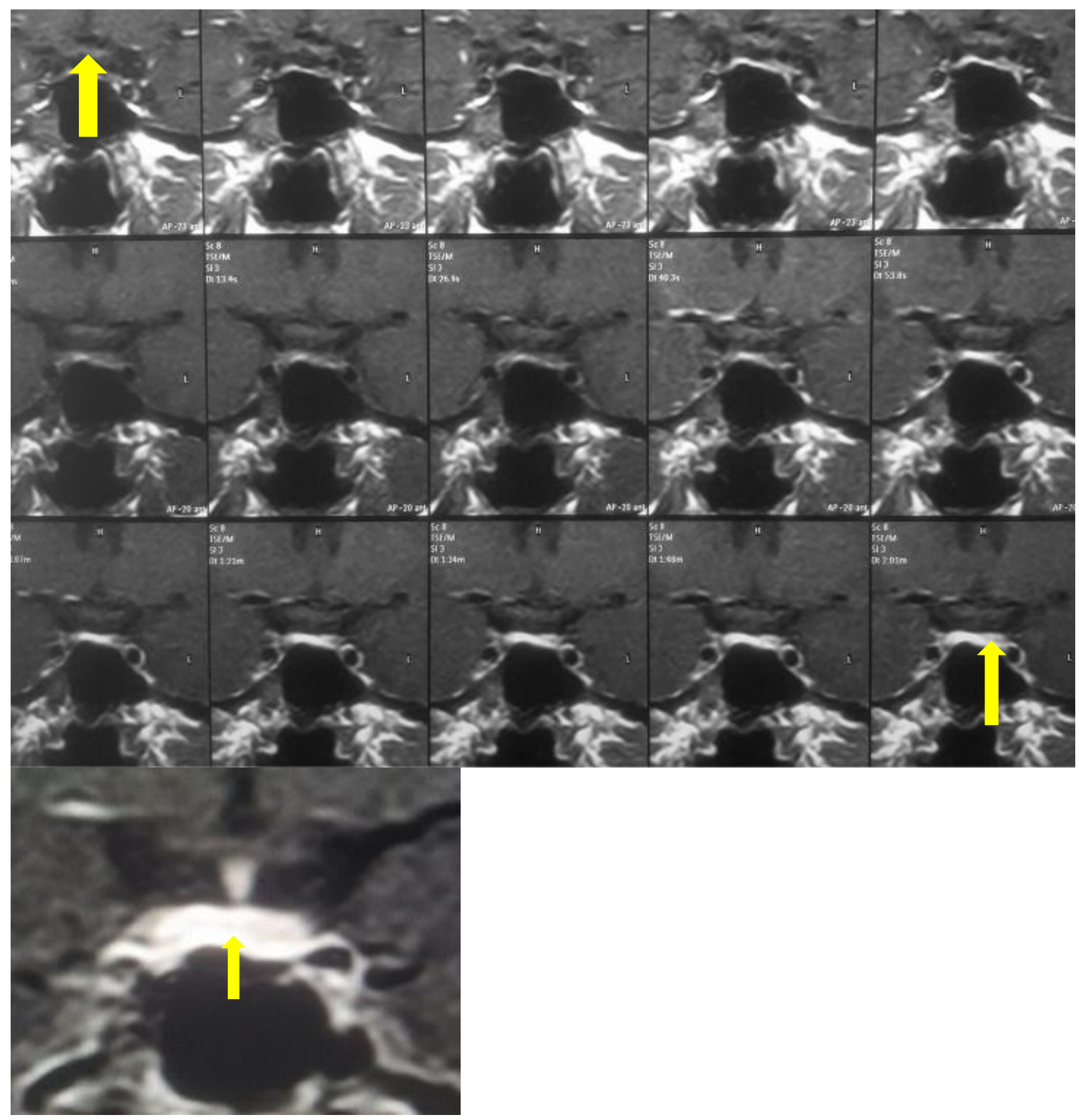

Figure 7: Dynamic Contrast MRI - gradual progressive enhancement (Yellow arrow) of normal pituitary on subsequent images resulting in homogenous enhancement 

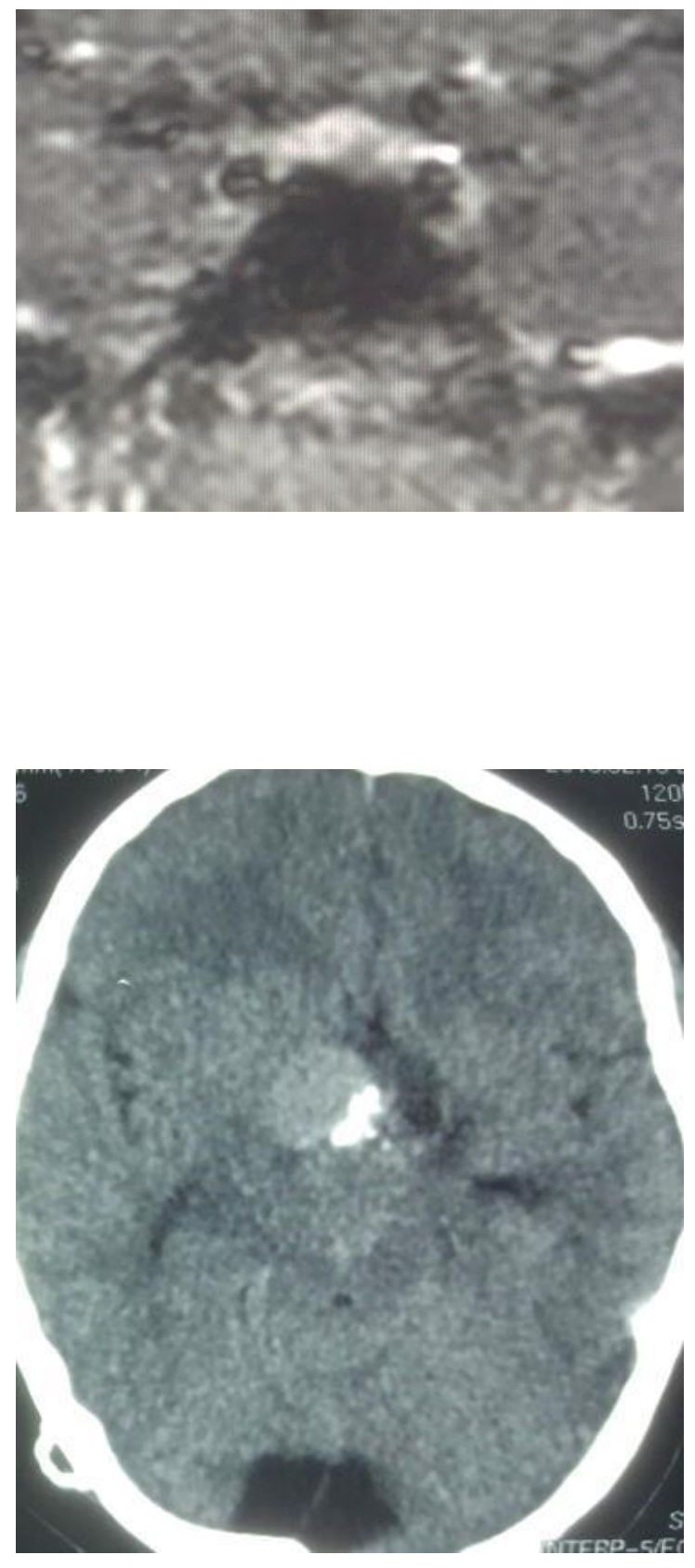

Figure 8: Microadenoma - a relatively non-enhancing lesion within a contrastenhanced pituitary

Figure 9: Calcifications in a craniopharyngioma 

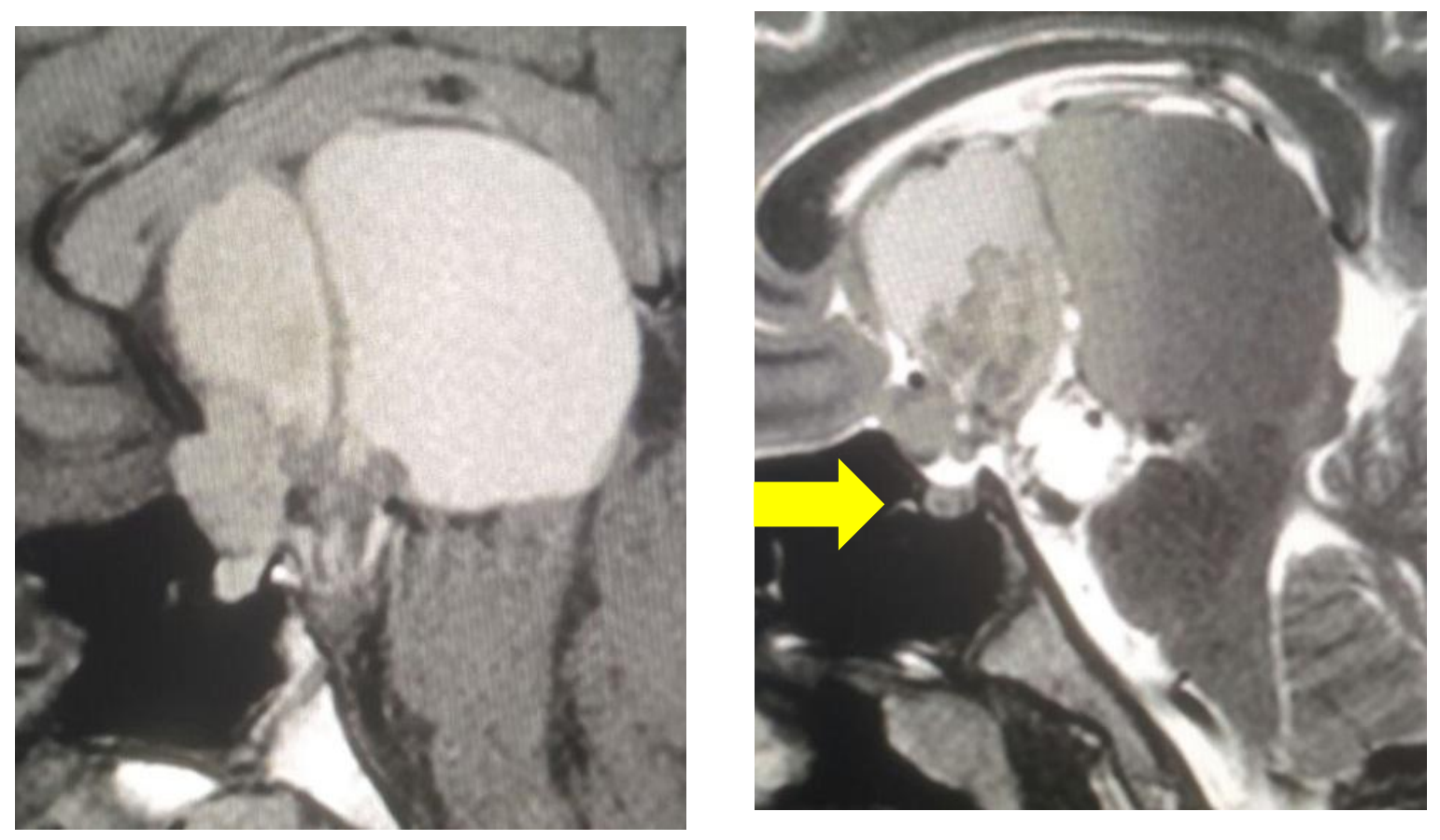

Figure 10: Craniopharyngioma (Yellow arrow). Pituitary gland separately identified

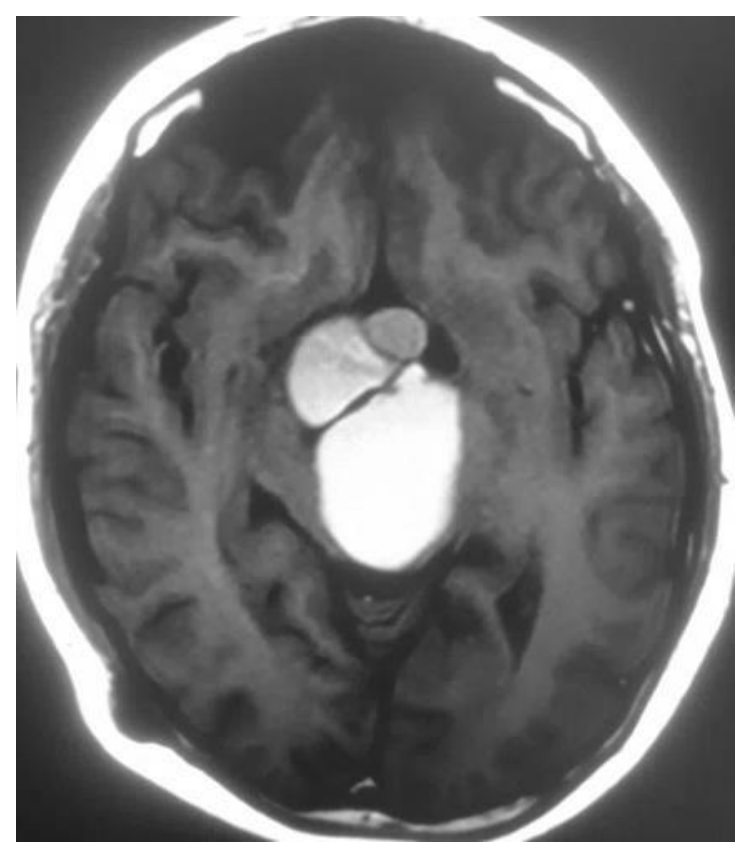

Figure 11: High T1 signal intensity cysts. The tumour was causing obstructive hydrocephalus requiring a VP shunt. 


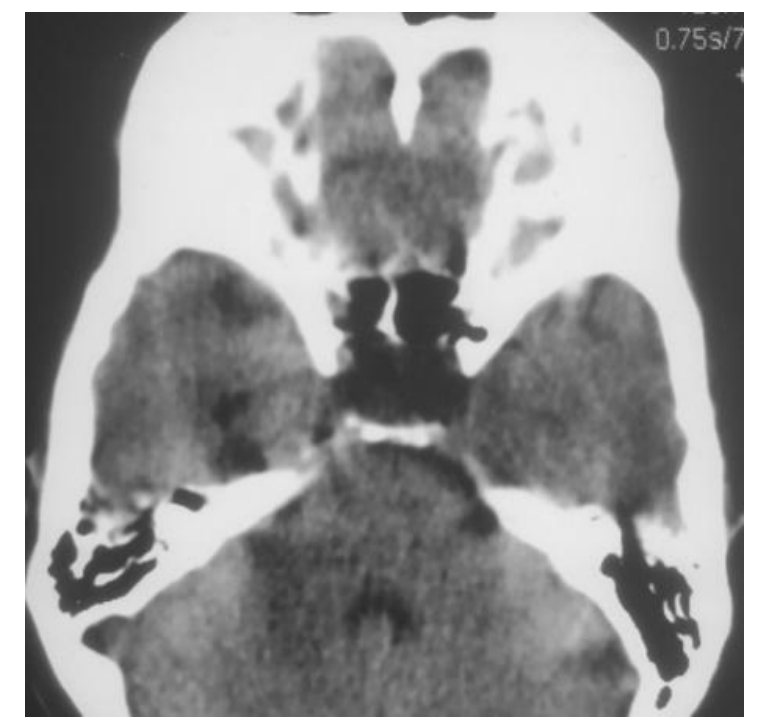

Figure 12:Rathke's cleft cyst
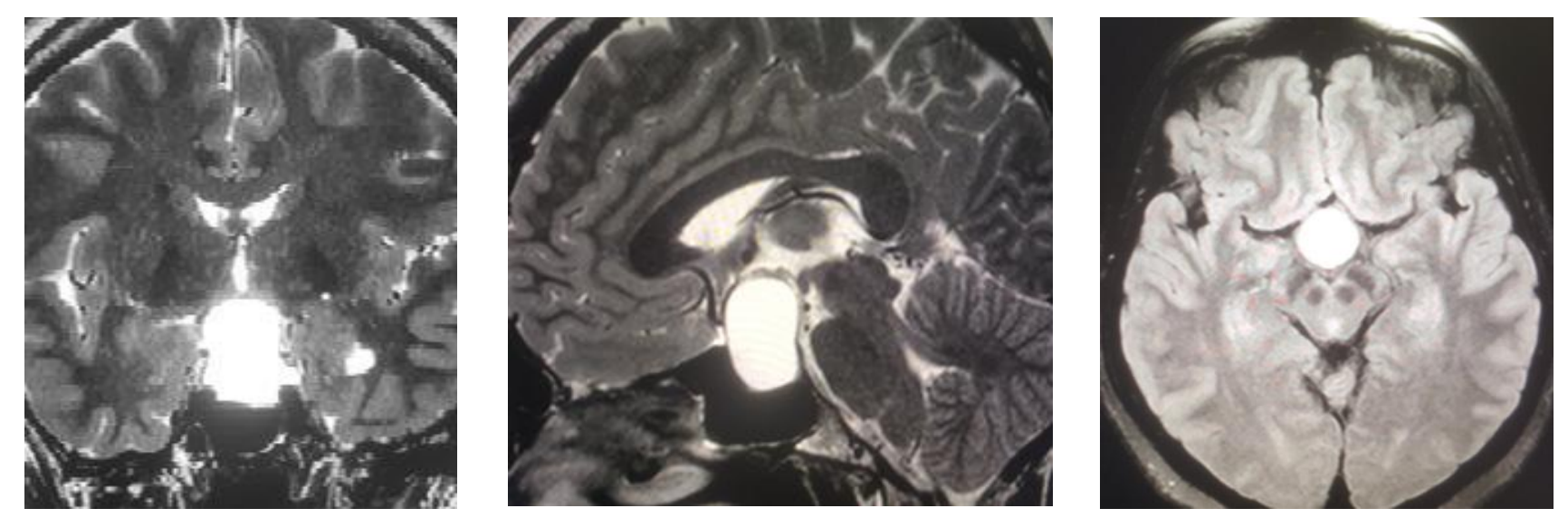

Figure 13: Rathke's cleft cyst; homogenous T2 signal intensity similar to CSF but with no suppression of signal on FLAIR image

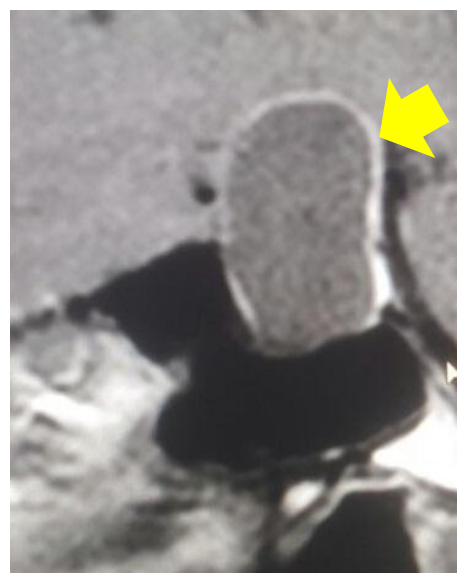

Figure 14: Enhancement of wall of a Rathke's cleft cyst 

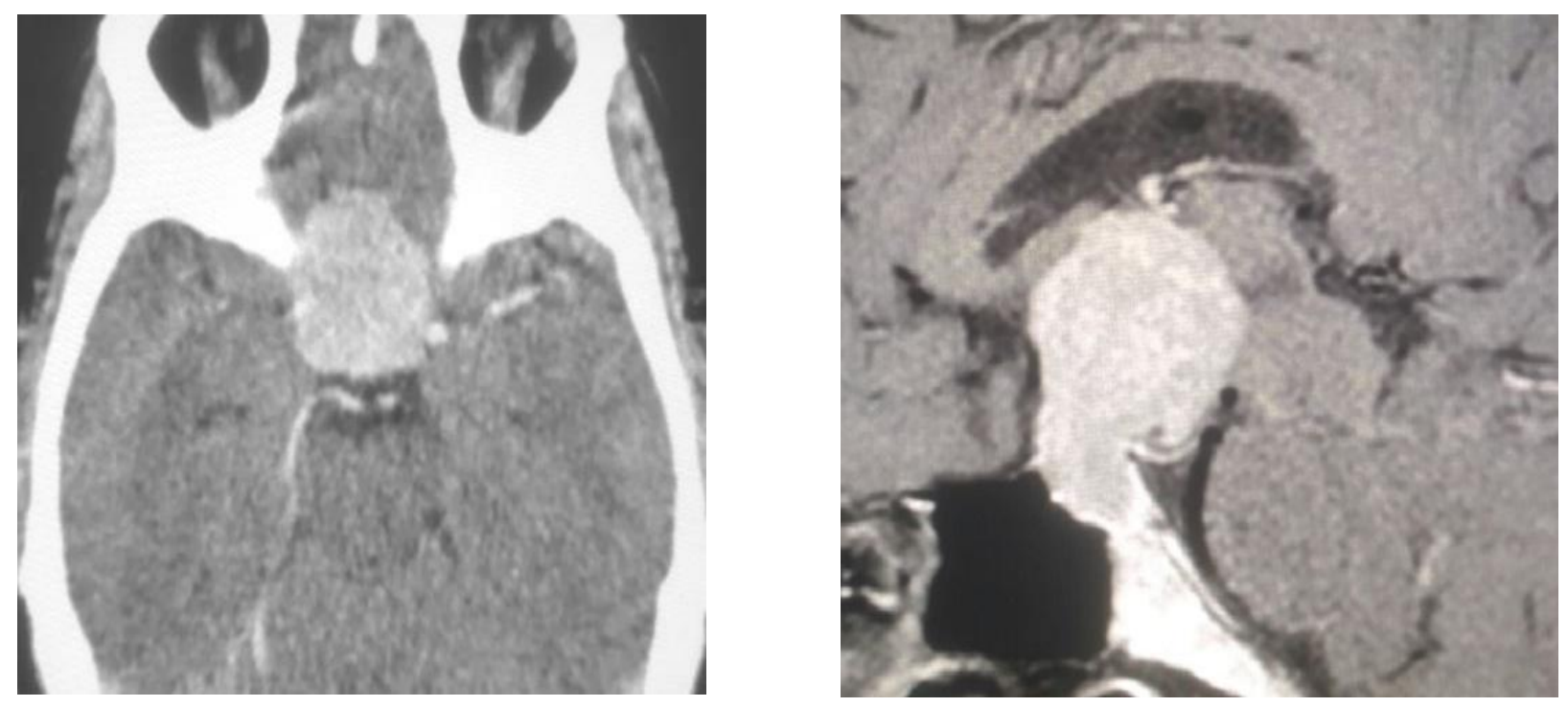

Figure 15: Suprasellar meningioma showing avid enhancement

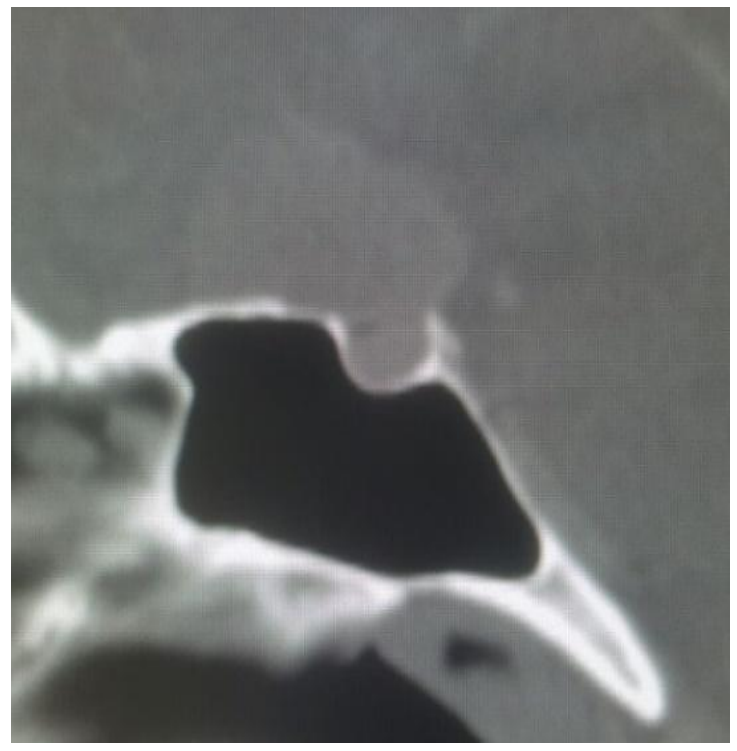

Figure 16: Bone window image showing no expansion of sella 

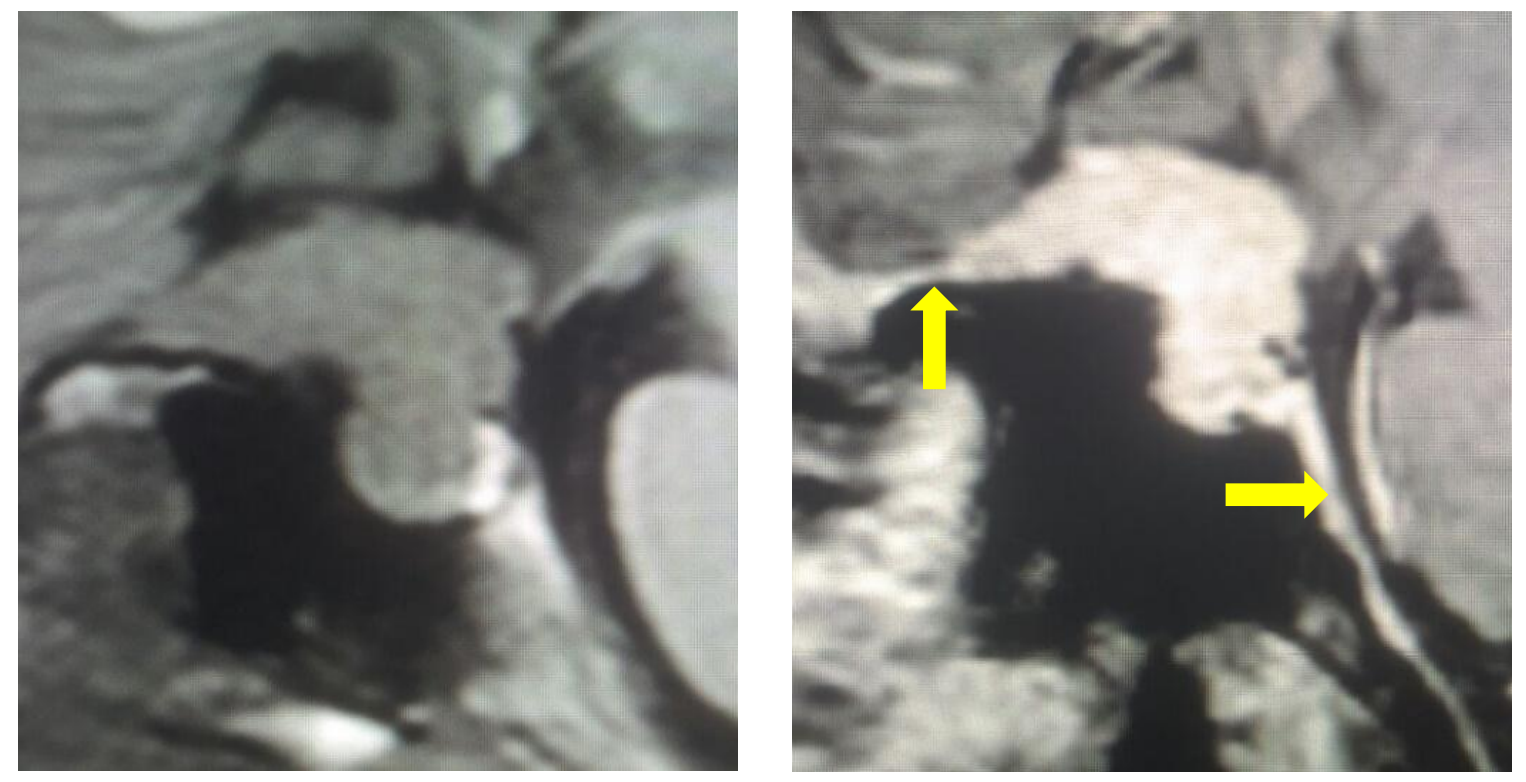

Figure 17: Vivid homogenous enhancement with dural tail (arrows)

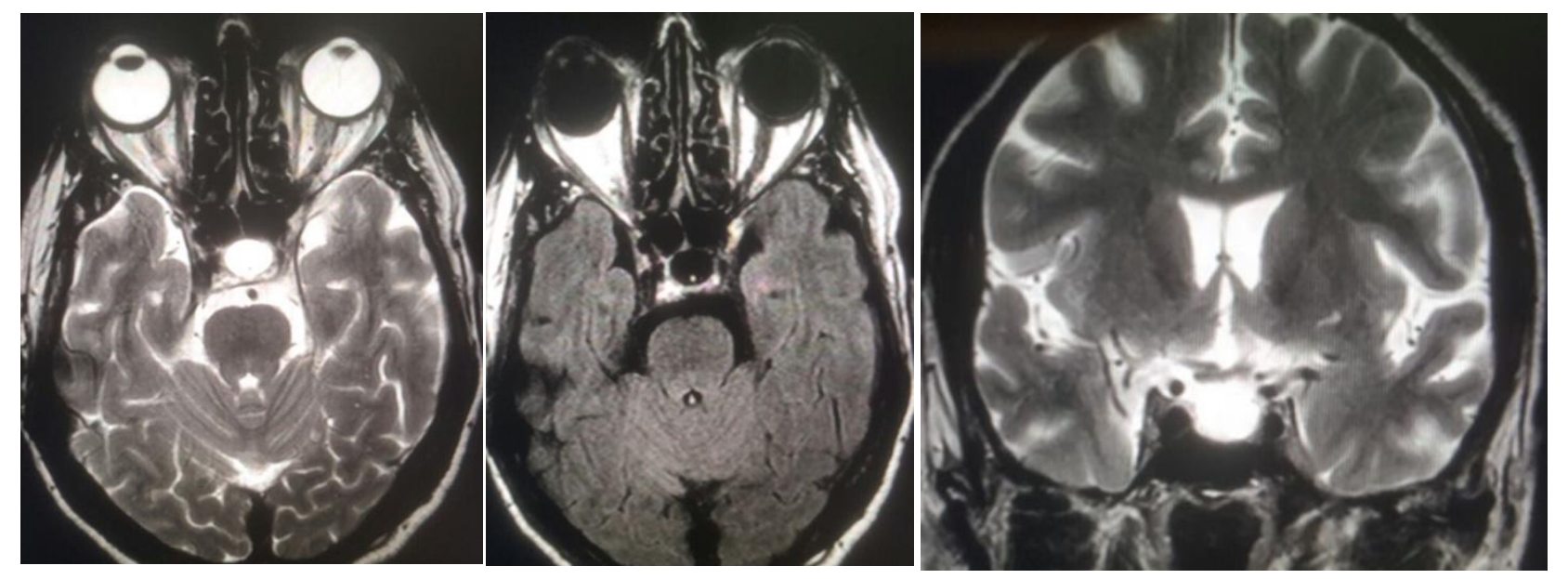

Figure 18: Fluid filling the sella, with FLAIR image confirming CSF. Note bright spot in the sella- the 'infundibulum sign' 

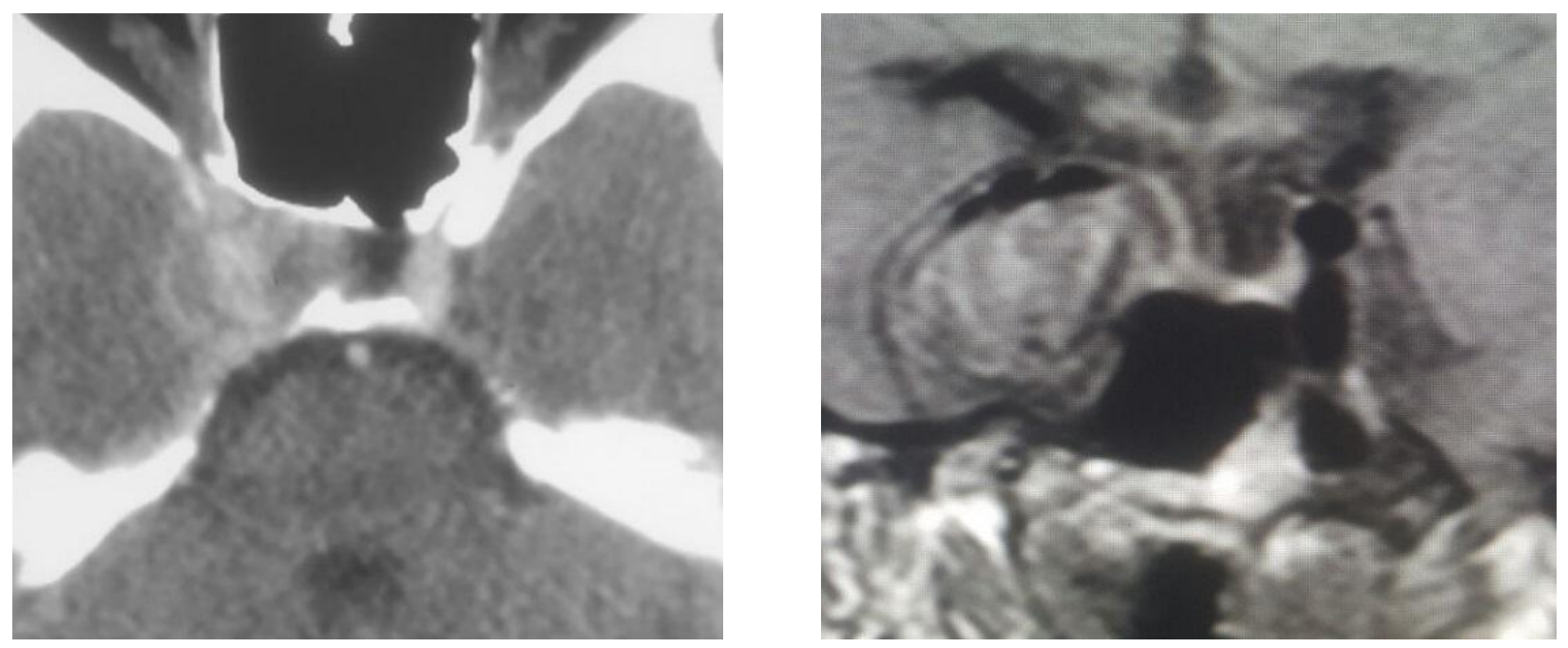

Figure 19: Heterogenous R/sided parasellar mass on CT. MRI revealed a R/ICA aneurysm
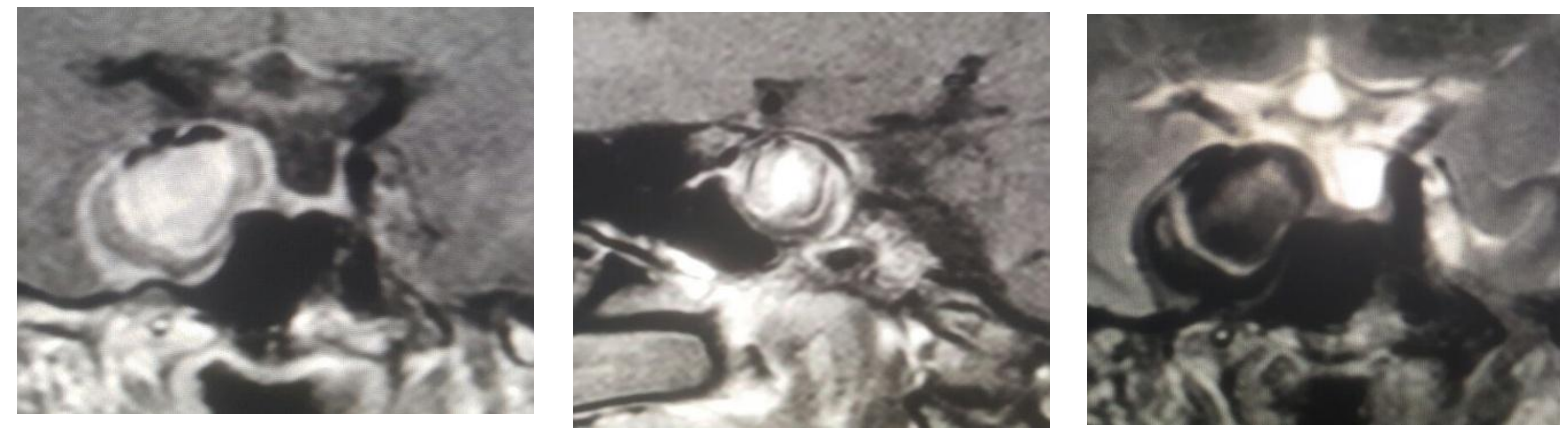

Figure 20: Partially thrombosed aneurysm in the $R /$ Cavernous sinus. Circumferential clot of different ages arranged in layers like an onion peel. 